\title{
X-ray powder diffraction analysis of a silver(I) cyclamate complex
}

\author{
R. Putvinskis and C. O. Paiva Santos \\ Laboratório Computacional de Análises Cristalográficas e Cristalinas - LabCACC, Instituto de Química, \\ UNESP, 14800-900, Rua Prof. Francisco Degni s/n, Araraquara, SP, Brazil \\ M. Cavicchioli and A. C. Massabni \\ Departamento de Química Geral e Inorgânica, Instituto de Química, UNESP, 14800-900, Rua Prof. \\ Francisco Degni s/n, Araraquara, SP, Brazil
}

(Received 4 January 2006; accepted 20 December 2006)

\begin{abstract}
X-ray powder diffraction data collected for the complex silver(I) cyclamate $\left[\mathrm{Ag}\left(\mathrm{C}_{6} \mathrm{H}_{12} \mathrm{NO}_{3} \mathrm{~S}\right)\right]$ are reported. This material was obtained from a stoichiometric mixture of sodium cyclamate and $\mathrm{AgNO}_{3}$. The analysis of the data using the Le Bail method showed that the complex has monoclinic symmetry (space group $C 2 / c$ ). The unit cell parameters are $a=31.85852(16) \AA, b=6.25257(6) \AA$, $c=8.46165(7) \AA$, and $\beta=95.7651(5)^{\circ}$. @ 2007 International Centre for Diffraction Data.
\end{abstract}

[DOI: $10.1154 / 1.2434342$ ]

Key words: silver(I), cyclamate, X-ray powder diffraction, Le Bail method

\section{INTRODUCTION}

Silver and several silver compounds have long been used as antimicrobial agents (Klasen, 2000a, b; De Gracia, 2001; Modak et al., 1983; Nomiya et al., 1995, 1997; Nomiya and Yokoyama, 2002). Particularly, silver(I)-sulfadiazine has been used clinically as an antimicrobial and antifungical agent. It is an insoluble polymeric compound that releases $\mathrm{Ag}(\mathrm{I})$ ions slowly, and is applied topically as a cream to prevent bacterial infections in cases of severe burns.

Sodium cyclamate (sodium cyclohexane-sulfamate, $\mathrm{NaC}_{6} \mathrm{H}_{12} \mathrm{NO}_{3} \mathrm{~S}$, see Figure 1) is a compound used as a commercial sweetener. In general, sweeteners have functional groups like carbonyl, carboxylate, amino, and sulfamate, which allow them to be used as ligands in coordination and bioinorganic chemistry. Cyclamate complexes, in general, exhibit low toxicity in humans and could be the basis of pharmaceutical products.

Considering that silver(I) compounds have antibacterial properties and that sodium cyclamate has low toxicity and low manufacture costs, a silver(I)-cyclamate complex was obtained in our laboratories. In fact, the compound reported in this paper showed a potent antimicobacterial activity against species of mycobacterium, including mycobacterium tuberculosis, which is responsible for tuberculosis infections. The other species tested were mycobacterium avium, mycobacterium intracellulare, mycobacterium malmoense, and mycobacterium kansasii (data not reported).

The aim of our work is to characterize the silver(I)cyclamate complex using a collection of techniques including X-ray powder diffraction. In this contribution, the X-ray powder diffraction data for silver(I) cyclamate, $\mathrm{Ag}\left(\mathrm{C}_{6} \mathrm{H}_{12} \mathrm{NO}_{3} \mathrm{~S}\right)$, are reported.

\section{EXPERIMENTAL}

Sodium cyclamate $(99.0 \%$ of purity) was purchased from Nutrasweet Kelco Company. Silver(I) nitrate is an Acros Organics Company product, of $99.8 \%$ purity. The compounds were used without further purification.
To synthesize the $\mathrm{Ag}\left(\mathrm{C}_{6} \mathrm{H}_{12} \mathrm{NO}_{3} \mathrm{~S}\right)$ complex, an aqueous solution of $\mathrm{AgNO}_{3}(0.340 \mathrm{~g}, 2.0 \mathrm{mmol})$ was added under stirring to a solution containing $0.402 \mathrm{~g}(2.0 \mathrm{mmol})$ of sodium cyclamate. White crystalline powders of the complex were obtained. The compound was washed with $200 \mathrm{~mL}$ of water and dried over $\mathrm{P}_{4} \mathrm{O}_{10}$ under vacuum.

Elemental analysis of carbon, hydrogen, nitrogen, and sulfur was performed using a CHNS-O EA1110 Analyzer, $\mathrm{CE}$ Instruments, and high purity cysteine was used as a reference substance. The silver content was determined by atomic absorption spectroscopy using an A Analyst 300 Perkin Elmer spectrometer. The infrared spectrum was recorded on a Spectrum 2000 FT-IR Perkin Elmer spectrophotometer from $\mathrm{KBr}$ pellets. Measured concentrations (wt.\%) for $\mathrm{C}_{6} \mathrm{H}_{12} \mathrm{AgO}_{3} \mathrm{NS}$ were determined to be $\mathrm{C}, 25.5 ; \mathrm{H}, 4.35 ; \mathrm{N}$, 5.04; S, 11.2; and Ag, 38.8\%, while the calculated concentrations are $\mathrm{C}, 25.2 ; \mathrm{H}, 4.23 ; \mathrm{N}, 4.89 ; \mathrm{S}, 11.2$; and $\mathrm{Ag}$, $37.7 \%$.

\section{INSTRUMENTATION}

$\mathrm{X}$-ray diffraction data were obtained using synchrotron radiation in the D10B-XPD line of the Laboratorio Nacional de Luz Sincrotron (LNLS) in Brazil. The experimental setup consisted of a Si (111) double-crystal monochromator with the first crystal refrigerated and the second sagitally curved. A scintillation detector was used. The monochromator was adjusted to select the energy $E=8.4995 \mathrm{keV}$ ( $\lambda$ $=1.45864 \AA$ ), that is the energy of maximum intensity at the LNLS in Brazil. $\theta-2 \theta$ geometry was used; a $\mathrm{Y}_{2} \mathrm{O}_{3}$ sample was used as reference material to check for the wavelength and instrumental broadening. The sample was deposited in a

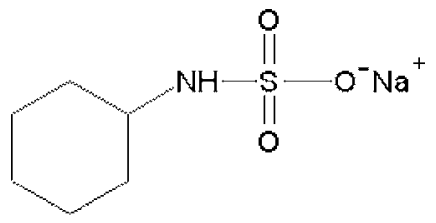

Figure 1. Schematic representation of sodium cyclamate. 
TABLE I. Best solutions obtained by the program Chekcell after analysis of the results obtained by Crysfire.

\begin{tabular}{lccccccc}
\hline \hline & Space groups & $a(\AA)$ & $b(\AA)$ & $c(\AA)$ & $\alpha\left(^{\circ}\right)$ & $\beta\left(^{\circ}\right)$ & $\gamma\left({ }^{\circ}\right)$ \\
\hline 1 & $C c, C a, C 2 / c$ & 31.858 & 6.251 & 8.459 & 90 & 95.75 & 90 \\
2 & $C c, C a, C 2 / c$ & 31.874 & 6.253 & 8.462 & 90 & 95.75 & 90 \\
\hline \hline
\end{tabular}

flat sample holder of $10 \times 12 \mathrm{~mm}^{2}$. Data were collected from 9 to $50{ }^{\circ} 2 \theta$, with step scan of $0.005^{\circ} 2 \theta$. The software XFit (Coelho and Cheary, 1997) was used to fit 46 peaks that were used for the indexing with the Crysfire suite (Shirley, 2002). The GSAS suite program (Larson and von Dreele, 2001) was used for the Le Bail fit. The Thompson-Cox-Hastings pseudo-Voigt function was used as the profile function. During the refinements, only the profile parameters that vary with $\sec \theta$ and $\operatorname{tg} \theta$ were refined.

\section{RESULTS AND DISCUSSION}

According to the elemental analysis for $\mathrm{C}, \mathrm{H}, \mathrm{N}$, and $\mathrm{S}$, the formula of the complex is $\left[\mathrm{Ag}\left(\mathrm{C}_{6} \mathrm{H}_{12} \mathrm{NO}_{3} \mathrm{~S}\right)\right]$. The main IR features of the cyclamate ligand are $3276 \mathrm{~cm}^{-1}(\mathrm{~s}, \nu$ $\mathrm{N}-\mathrm{H}), 2977-2854 \mathrm{~cm}^{-1}(\mathrm{~s}, \nu \mathrm{C}-\mathrm{H}$ of ring and aliphatic ring), $1488 \mathrm{~cm}^{-1}\left(\mathrm{~m}, \delta \mathrm{C}-\mathrm{H}\right.$ of aliphatic ring), $1246 \mathrm{~cm}^{-1}$ $(\mathrm{m}, \delta \mathrm{C}-\mathrm{N}), 1213 \mathrm{~cm}^{-1}$ (w, $\delta_{\text {ass. }} \mathrm{SO}_{2}$ group), and $1054 \mathrm{~cm}^{-1}$ (w, $\delta_{\text {sym. }} \mathrm{SO}_{2}$ group) (Silverstein et al., 1991). The comparison of the IR spectrum of the silver-complex with that of the sodium cyclamate indicates that the ligand is coordinated to $\operatorname{Ag}(\mathrm{I})$ through the nitrogen of the secondary amine and the oxygen of the sulfamate group.

The analysis of the diffraction data with Crysfire and Chekcell resulted in two solutions, each one with three possible space groups (Table I). All solutions were used for the Le Bail fit and the agreement factors for all six fits are in Table II. Lower $\chi^{2}$ values were obtained for the first solution with the space group $C 2 / c$, and the unit cell parameters for this case are $a=31.85195(19) \AA, b=6.25087(6) \AA, c$ $=8.45970(6) \AA$, and $\beta=95.765(0)^{\circ}$. The relative intensities for the best fit are in Table III. The powder diffraction data, after the indexing, are shown in Table III. The results of the profile fit are shown in Figure 2.

Density measurements (pycnometric determination under helium, after a careful evacuation) were used to determine an experimental density of $2.375 \mathrm{~g} / \mathrm{cm}^{3}$. This experi-

TABLE II. Agreement factors after Le Bail fit for each solution described in Table I and unit cell parameters for the best Le Bail fit.

\begin{tabular}{cccc}
\hline \hline From solution no. & & $R w p$ & $\chi^{2}$ \\
\hline \multirow{2}{*}{1} & $C a$ & 9.45 & 2.056 \\
& $C c$ & 9.46 & 2.059 \\
& $C 2 / c^{\mathrm{a}}$ & 9.30 & 1.191 \\
& $C a$ & 9.80 & 2.209 \\
& & & \\
2 & $C c$ & 9.66 & 2.152 \\
& $C 2 / c$ & 9.44 & 2.050 \\
\hline
\end{tabular}

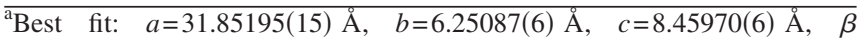
$=95.765^{\circ}, V=1675.828(20) \AA^{3}$.
TABLE III. Powder X-ray diffraction data for the Ag(I)-cyclamate complex.

\begin{tabular}{|c|c|c|c|c|c|c|c|c|c|}
\hline$h$ & $k$ & $l$ & $d$ & $I$ & $h$ & $k$ & $l$ & $d$ & $I$ \\
\hline 4 & 0 & 0 & 7.923 & 999 & 2 & 0 & -4 & 2.114 & 0 \\
\hline 1 & 1 & 0 & 6.133 & 3 & 0 & 0 & 4 & 2.104 & 13 \\
\hline 3 & 1 & 0 & 5.379 & 11 & 2 & 2 & -3 & 2.090 & 24 \\
\hline 6 & 0 & 0 & 5.282 & 80 & 0 & 2 & 3 & 2.088 & 4 \\
\hline 1 & 1 & -1 & 5.003 & 3 & 4 & 0 & -4 & 2.086 & 2 \\
\hline 1 & 1 & 1 & 4.911 & 20 & 14 & 0 & -2 & 2.083 & 25 \\
\hline 3 & 1 & -1 & 4.642 & 38 & 13 & 1 & -2 & 2.082 & 48 \\
\hline 5 & 1 & 0 & 4.450 & 36 & 1 & 3 & 0 & 2.079 & 1 \\
\hline 3 & 1 & 1 & 4.431 & 73 & 8 & 2 & 2 & 2.065 & 25 \\
\hline 0 & 0 & 2 & 4.208 & 6 & 2 & 0 & 4 & 2.059 & 16 \\
\hline 2 & 0 & -2 & 4.173 & 88 & 4 & 2 & -3 & 2.057 & 0 \\
\hline 5 & 1 & -1 & 4.054 & 5 & 2 & 2 & 3 & 2.050 & 7 \\
\hline 2 & 0 & 2 & 3.970 & 141 & 3 & 3 & 0 & 2.044 & 6 \\
\hline 8 & 0 & 0 & 3.961 & 347 & 10 & 2 & -2 & 2.027 & 5 \\
\hline 4 & 0 & -2 & 3.882 & 36 & 6 & 0 & -4 & 2.026 & 1 \\
\hline 5 & 1 & 1 & 3.824 & 0 & 1 & 3 & -1 & 2.022 & 9 \\
\hline 7 & 1 & 0 & 3.667 & 134 & 12 & 2 & 0 & 2.017 & 24 \\
\hline 4 & 0 & 2 & 3.571 & 24 & 1 & 3 & 1 & 2.015 & 7 \\
\hline 1 & 1 & -2 & 3.502 & 10 & 11 & 1 & -3 & 2.007 & 21 \\
\hline 7 & 1 & -1 & 3.466 & 31 & 1 & 1 & -4 & 2.002 & 36 \\
\hline 6 & 0 & -2 & 3.465 & 168 & 15 & 1 & 0 & 2.001 & 2 \\
\hline 1 & 1 & 2 & 3.439 & 122 & 12 & 2 & -1 & 1.997 & 41 \\
\hline 3 & 1 & -2 & 3.400 & 0 & 3 & 3 & -1 & 1.995 & 34 \\
\hline 7 & 1 & 1 & 3.266 & 0 & 3 & 1 & -4 & 1.995 & 16 \\
\hline 3 & 1 & 2 & 3.235 & 163 & 6 & 2 & -3 & 1.993 & 4 \\
\hline 5 & 1 & -2 & 3.171 & 31 & 15 & 1 & -1 & 1.990 & 12 \\
\hline 10 & 0 & 0 & 3.169 & 252 & 9 & 1 & 3 & 1.986 & 15 \\
\hline 6 & 0 & 2 & 3.141 & 37 & 4 & 0 & 4 & 1.985 & 2 \\
\hline 0 & 2 & 0 & 3.125 & 22 & 4 & 2 & 3 & 1.983 & 1 \\
\hline 9 & 1 & 0 & 3.068 & 218 & 16 & 0 & 0 & 1.981 & 7 \\
\hline 2 & 2 & 0 & 3.066 & 28 & 5 & 3 & 0 & 1.979 & 19 \\
\hline 8 & 0 & -2 & 3.041 & 131 & 1 & 1 & 4 & 1.979 & 11 \\
\hline 9 & 1 & -1 & 2.967 & 12 & 3 & 3 & 1 & 1.978 & 4 \\
\hline 5 & 1 & 2 & 2.955 & 107 & 5 & 1 & -4 & 1.956 & 48 \\
\hline 0 & 2 & 1 & 2.930 & 29 & 8 & 0 & -4 & 1.941 & 7 \\
\hline 4 & 2 & 0 & 2.907 & 18 & 5 & 3 & -1 & 1.940 & 4 \\
\hline 2 & 2 & -1 & 2.899 & 5 & 12 & 2 & 1 & 1.928 & 0 \\
\hline 7 & 1 & -2 & 2.883 & 83 & 3 & 1 & 4 & 1.926 & 10 \\
\hline 2 & 2 & 1 & 2.863 & 35 & 13 & 1 & 2 & 1.925 & 85 \\
\hline 9 & 1 & 1 & 2.804 & 40 & 14 & 0 & 2 & 1.915 & 8 \\
\hline 4 & 2 & -1 & 2.780 & 0 & 5 & 3 & 1 & 1.913 & 4 \\
\hline 8 & 0 & 2 & 2.750 & 47 & 10 & 2 & 2 & 1.912 & 10 \\
\hline 4 & 2 & 1 & 2.717 & 43 & 15 & 1 & 1 & 1.907 & 25 \\
\hline 6 & 2 & 0 & 2.690 & 31 & 8 & 2 & -3 & 1.907 & 25 \\
\hline 10 & 0 & -2 & 2.663 & 73 & 6 & 2 & 3 & 1.894 & 6 \\
\hline 7 & 1 & 2 & 2.659 & 41 & 7 & 3 & 0 & 1.893 & 7 \\
\hline 12 & 0 & 0 & 2.641 & 335 & 7 & 1 & -4 & 1.893 & 9 \\
\hline 11 & 1 & 0 & 2.616 & 177 & 6 & 0 & 4 & 1.891 & 13 \\
\hline 6 & 2 & -1 & 2.601 & 7 & 15 & 1 & -2 & 1.878 & 32 \\
\hline 9 & 1 & -2 & 2.589 & 80 & 1 & 3 & -2 & 1.869 & 2 \\
\hline 1 & 1 & -3 & 2.570 & 1 & 16 & 0 & -2 & 1.866 & 20 \\
\hline
\end{tabular}




\begin{tabular}{|c|c|c|c|c|c|c|c|c|c|}
\hline$h$ & $k$ & $l$ & $d$ & $I$ & $h$ & $k$ & $l$ & $d$ & $I$ \\
\hline 11 & 1 & -1 & 2.566 & 11 & 1 & 3 & 2 & 1.859 & 2 \\
\hline 3 & 1 & -3 & 2.541 & 0 & 3 & 3 & -2 & 1.853 & 4 \\
\hline 1 & 1 & 3 & 2.533 & 3 & 5 & 1 & 4 & 1.852 & 2 \\
\hline 6 & 2 & 1 & 2.525 & 41 & 13 & 1 & -3 & 1.852 & 1 \\
\hline 0 & 2 & 2 & 2.509 & 1 & 10 & 0 & -4 & 1.840 & 9 \\
\hline 2 & 2 & -2 & 2.501 & 12 & 14 & 2 & 0 & 1.833 & 39 \\
\hline 2 & 2 & 2 & 2.456 & 2 & 11 & 1 & 3 & 1.832 & 4 \\
\hline 8 & 2 & 0 & 2.454 & 0 & 7 & 3 & 1 & 1.830 & 0 \\
\hline 5 & 1 & -3 & 2.453 & 1 & 3 & 3 & 2 & 1.825 & 3 \\
\hline 3 & 1 & 3 & 2.437 & 4 & 14 & 2 & -1 & 1.822 & 16 \\
\hline 11 & 1 & 1 & 2.436 & 11 & 5 & 3 & -2 & 1.813 & 1 \\
\hline 4 & 2 & -2 & 2.434 & 9 & 9 & 1 & -4 & 1.811 & 0 \\
\hline 10 & 0 & 2 & 2.418 & 51 & 10 & 2 & -3 & 1.807 & 2 \\
\hline 8 & 2 & -1 & 2.396 & 35 & 9 & 3 & 0 & 1.793 & 4 \\
\hline 9 & 1 & 2 & 2.382 & 0 & 8 & 2 & 3 & 1.793 & 0 \\
\hline 4 & 2 & 2 & 2.352 & 10 & 17 & 1 & 0 & 1.786 & 25 \\
\hline 12 & 0 & -2 & 2.345 & 4 & 8 & 0 & 4 & 1.785 & 1 \\
\hline 7 & 1 & -3 & 2.321 & 32 & 17 & 1 & -1 & 1.783 & 6 \\
\hline 6 & 2 & -2 & 2.321 & 38 & 9 & 3 & -1 & 1.772 & 2 \\
\hline 11 & 1 & -2 & 2.319 & 82 & 12 & 2 & 2 & 1.767 & 11 \\
\hline 8 & 2 & 1 & 2.317 & 15 & 7 & 1 & 4 & 1.764 & 10 \\
\hline 5 & 1 & 3 & 2.301 & 4 & 14 & 2 & 1 & 1.762 & 7 \\
\hline 13 & 1 & 0 & 2.271 & 74 & 18 & 0 & 0 & 1.761 & 13 \\
\hline 14 & 0 & 0 & 2.264 & 39 & 7 & 3 & -2 & 1.754 & 2 \\
\hline 13 & 1 & -1 & 2.246 & 2 & 2 & 2 & -4 & 1.751 & 1 \\
\hline 10 & 2 & 0 & 2.225 & 20 & 0 & 2 & 4 & 1.745 & 17 \\
\hline 6 & 2 & 2 & 2.216 & 17 & 15 & 1 & 2 & 1.744 & 93 \\
\hline 10 & 2 & -1 & 2.190 & 31 & 9 & 3 & 1 & 1.736 & 5 \\
\hline 8 & 2 & -2 & 2.180 & 46 & 4 & 2 & -4 & 1.735 & 2 \\
\hline 9 & 1 & -3 & 2.167 & 28 & 12 & 0 & -4 & 1.733 & 4 \\
\hline 7 & 1 & 3 & 2.145 & 3 & 14 & 2 & -2 & 1.733 & 9 \\
\hline 13 & 1 & 1 & 2.143 & 39 & 16 & 0 & 2 & 1.727 & 13 \\
\hline 12 & 0 & 2 & 2.142 & 50 & 2 & 2 & 4 & 1.719 & 19 \\
\hline 11 & 1 & 2 & 2.136 & 20 & 11 & 1 & -4 & 1.718 & 20 \\
\hline
\end{tabular}

mental value, combined with the molar mass of the complex, allowed for the calculation of the number of formula weight contained in a cell, equal to $8(Z=8)$.

\section{CONCLUSION}

A new silver(I)-cyclamate complex that presents a potent antimicobacterial activity against species of mycobacterium, including mycobacterium tuberculosis, has been prepared and characterized using X-ray powder diffraction. The formula of the complex, determined by elemental analysis, is $\mathrm{Ag}\left(\mathrm{C}_{6} \mathrm{H}_{12} \mathrm{NO}_{3} \mathrm{~S}\right)$. At room temperature the silver(I)cyclamate complex has monoclinic symmetry with unit

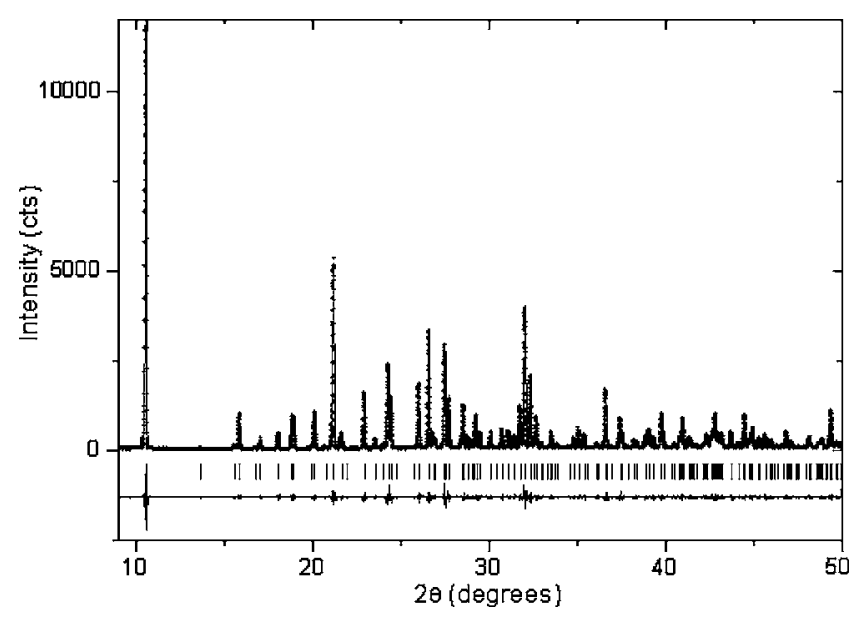

Figure 2. Observed (dots), fitted (continuous line), and difference (bottom line) diffractograms for silver(I)-cyclamate. The small vertical lines above the difference plot are the Bragg peak positions.

cell parameters $a=31.85852(16) \AA, \quad b=6.2526(6) \AA$, $c=8.46165(7) \AA$, and $\beta=95.7651(5)^{\circ}$, with three space groups being possible $(C 2 / c, C c, C a)$. Crystal structure determination is necessary for the definition of the space group.

\section{ACKNOWLEDGMENTS}

The authors are grateful to Fundação de Amparo à Pesquisa do Estado de São Paulo (FAPESP) and Conselho Nacional de Desenvolvimento Científico e Tecnológico (CNPq) for financial support.

Coelho, A. A. and Cheary, R. W. (1997). X-ray Line Profile Fitting Program, XFIT. School of Physical Sciences, University of Technology, Sydney, New South Wales, Australia.

De Gracia, C. G. (2001). "An open study comparing topical silver sulfadiazine and topical silver sulfadiazine-cerium nitrate in the treatment of moderate and sever burns," Burns 27, 67-74.

Klasen, H. J. (2000a). "Historical review of the use of silver in the treatment of burns, I. Early uses," Burns 26, 117-130.

Klasen, H. J. (2000b). "A historical review of the use of silver in the treatment of burns, II. Renewed interest for silver," Burns 26, 131-138.

Larson, A. C. and von Dreele, R. B. (2001). "GSAS - General Structure Analysis System," Los Alamos National Laboratory. Los Alamos, EUA. Copyright 1985-2000, The Regents of the University of California.

Modak, S., Stanford, J., Friendlaender, J., Fox, P., and Fox, C. L. (1983). "Control of burn wound infections by pentafloxacin and its silver derivative," Burns 10, 170-178.

Nomiya, K., Kondoh, Y., Onoue, K., Kasuga, N. C., Nagano, H., Oda, M., Sudoh, T., and Sakuma, S. (1995). "Synthesis and characterization of polymeric, anionic thiosalicylato- $\mathrm{Ag}(\mathrm{I})$ complexes with antimicrobial activities," J. Inorg. Biochem. 58, 255-267.

Nomiya, K., Tsuda, K., Sudoh, T., and Oda, M. (1997). "Ag(I)-N bondcontaining compound showing wide spectra in effective antimicrobial activities: polymeric silver(I) imidazolate," J. Inorg. Biochem. 68, 3944.

Nomiya, K. and Yokoyama, H. (2002). "Synthesis, crystal structures and antimicrobial activities of polymeric silver(I) complexes with three amino-acids [aspartic acid ( $\left.\mathrm{H}_{2} \mathrm{asp}\right)$, glycine (Hgly) and asparagine (Hasn)]," J. Chem. Soc. Dalton Trans. 12, 2483-2490.

Shirley, R. (2002). The Crysfire 2002 System for Automatic Powder Indexing: User's Manual (Lattice, Guildford, England).

Silverstein, R. M., Bassler, G. C., and Morrill, T. C. (1991). Spectrometric Identification of Organic Compounds, 5th ed. (Wiley, Singapore). 